\title{
The antigen presentation function of bone marrow-derived mast cells is spatiotemporally restricted to a subset expressing high levels of cell surface FcERI and MHC II
}

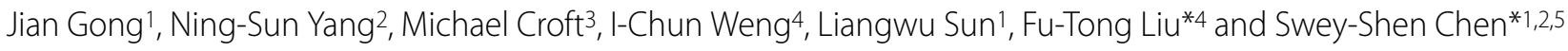

\begin{abstract}
Background: At present, it is highly controversial whether pure mast cells can serve as antigen presenting cells, and it is not known whether the capacity of antigen presenting function is temporally restricted to a particular subset of differentiated mast cells. Evidence is presented for a novel surface FceR/hi, MHC II +, and c-kit + pure mast cell subset, temporally restricted as antigen-presenting cells in the immune axis of T-cell activation.

Results: Bone marrow-derived mast cells (BMMC) cultured in the presence of IL-3 for three weeks are pure mast cells based on surface expression of lineage-specific marker, c-kit and FcERI. Herein we present the first demonstration that approximately 98.7\% c-kit + and FcERl expressing BMMC, further depleted of any contaminated professional antigenpresenting cells, are still fully capable of presenting antigens, i.e., OVA protein, OVA peptide, and IgE-TNP-OVA, to OVA peptide-specific T-cell hybridomas. Notably, IgE-dependent antigen presentation is more efficient compared to that resulting from direct antigen uptake. Importantly, we present the novel finding that only surface FcER/hi mast cells, also expressing surface $\mathrm{MHC}$ II exhibited antigen-presenting function. In contrast, surface FcERllo mast cells without expressing surface MHC II were not capable of antigen presentation. Interestingly, the antigen-presenting function of BMMC was irrevocably lost during the third and fourth week in IL-3 or SCF containing cultures.

Conclusions: This is the first observation to attribute a spatiotemporally restricted antigen-presenting function to a subset of three-week old pure BMMC expressing both high levels of surface FcERI and surface MHC II. We propose that mast cells play an important role in immune deviating and/or sustaining the activation of infiltrating CD4 T-cells, and modulating T-cell mediated allergic inflammation via its flexibility to present antigens and antigen-lgE complexes.
\end{abstract}

\section{Background}

Mast cells are traditionally thought of as a secretory cell type releasing inflammatory mediators in IgE-dependent inflammation[1,2]. Their role in innate immunity against pathogens has been uncovered, which is associated with their uptake and clearance of the microbes [3,4]. Mast cells undergo maturation and specialization in different tissue compartments [5-7]. Adoptively transferred progenitors of mast cells from fetal liver and bone marrow

* Correspondence: fliu@ucdavis.edu, alex@ige-therapeutics.com

4 Department of Dermatology, University of California-Davis, Sacramento, CA, USA

1 Department of Allergy and Immunology, IgE Therapeutics, Inc., San Diego, CA, USA

Full list of author information is available at the end of the article repopulate the skin and mucosa of intestine and lung in mast cell-deficient mice as connective-tissue type as well as mucosal type mast cells, distinguished by the granular content and safranin-based staining [5-7].

Although early studies have shown that bone marrowderived mast cells (BMMC) are capable of presenting bacterial and protein antigens via MHC class I and MHC II pathways [8,9], the purity of mast cells used and whether all BMMC are capable of antigen presentation are not known. Herein, we showed that close to $99 \%$ (98.7\%) pure, c-kit + BMMC obtained by culturing bone marrow cells in IL-3-containing medium for three-week, followed by removal of putative contaminating antigenpresenting cells (APC), are fully capable of antigen pre- 
sentation. Herein, we present a novel finding that only the BMMC subset expressing high levels of FceRI, concomitantly with high levels of MHC II on the cell surface, is capable of antigen presentation, whereas another BMMC subset expressing low levels of surface FceRI and no detectable cell surface MHC II, fails to present antigens. Moreover, the temporally restricted APC function of BMMC indicates a flexibility of mast cells in playing a role in CD4 T-cell dichotomy and/or sustaining CD4 Tcell activation.

\section{Methods}

\section{Reagents and chemicals}

OVA $^{323-339}$ (OVAp; ISQAVHAAHAEINEAGR) and pigeon cytochrome c peptide (PCCP; KAERADLIAYLKQATAK) were synthesized on a Rainin Symphony (Peptide Technologies, Tucson, AZ) synthesizer. Rabbit anti-histamine antibody and Texas red-strepavidin were purchased from Sigma (ST. Louis, MO). $\left[{ }^{3} \mathrm{H}\right]$-thymidine was purchased from Amersham. The $\mathrm{T}$ cell hybridoma lines used include: 1) 3Do-54.8, which was provided by Dr. P. Marrack at University of Colorado (Denver, CO) and 2) AD10, restricted to $\mathrm{PCC}^{88-104}$ (PCCP) and $\mathrm{IE}^{\mathrm{k}}$, which was obtained from Dr. S. Hedrick at University of California at San Diego. A20 (H-2d) and DECK.ICAM $\left(\mathrm{H}-2^{\mathrm{k}}\right)$, which were originally transfected with I-Ek by Dr. R. Germain, NIH, and further transfected with ICAM-1 by Dr. P. Kuhlman, La Jolla Cancer Research, were employed as APC.

Recombinant GM-CSF and IL-3 were purchased from Genzyme Corp. (Cambridge, MA). TNP-OVA and DNPspecific IgE prepared from IgE-secreting hybridoma, 26.82 were prepared in our laboratory as described [10]. Antigen-IgE complexes were prepared by incubating TNP-OVA and IgE at the same concentrations (wt/wt) for $30 \mathrm{~min}$ at room temperature. The following reagents were purchased from BD PharMingen (SD, CA): MAbs anti-B220/CD45R (RA3-6B2), anti-IAd (39-10-8, IgG3/א), anti-IEk (17-3-3, IgG2a/א), anti-CD16/32 (2.4G2), antiCD54 (ICAM-1, 3E2), anti-CD49d (integrin $\alpha 4, \mathrm{R} 1-2)$, anti-CD29 (integrin $\beta 1, \mathrm{Ha} 2 / 5$ ), anti-CD11a (integrin $\alpha_{\mathrm{L}}$, LFA-1 $\alpha$ chain, 2D7), allophycocyanin-conjugated antimouse c-kit/CD117 (2B8), FITC-murine control monoclonal IgG1, PE-murine control mIgG1, FITC-rat mIgG1 control and FITC-streptavidin. Anti-CD11c (N418) was obtained from Miltenyi Biotec (Auburn, CA). Hybridoma F4/80 secreting MAb directed against macrophages/ monocytes, is a generous gift from Dr. S. Gordon at Oxford University [11]. Hybridomas secreting MAb antiFceRI (TW) was obtained from the laboratory of Professor David Holowka at Cornell University (Ithaca, NY). The MAb was previously shown by us to bind to FceRI $\alpha$ [12]. FITC conjugate of TW was prepared in the labora- tory. WEHI-3 constitutively secreting IL-3 was provided by Dr. J. W. Schrader at the University of British Columbia (Vancouver, Canada), and D11 hybridoma secreting IL-3 was provided by Dr. N. Arai at DNAX Research Institute (Palo Alto, CA). Recombinant SCF was obtained from Dr. T. Huff (Virginia Commonwealth Univ, Richmond, VA) [13]. To perform depletion of putative contaminating APC, the reagents were purchased from Miltenyi Biotec (Auburn, CA): anti-B220, and F4/80 antimacrophage/monocytes, and anti-CD11c (N418 for DC) and mouse anti-rat kappa light chain (MAR18.5) coupled to magnetic MicroBeads ${ }^{\mathrm{ma}}$. Procedures were followed according to this vendor.

\section{BMMC cultures and differential staining}

Femurs were collected from three to six-week old female DBA/2 (H-2d), BALB/c (H-2d) or C3H (H-2k) mice (Jackson Lab, Bar Harbor, ME). Marrows were compressed out from the bone cavities with a steady stream of RPMI from a syringe fitted with a 27-gauge needle. Cells were gently spread out and cultured in two 75 -flasks in 20\% WEHI-3or D11-conditioned medium in 10\% fetal bovine serum (FBS). Non-adherent cells were transferred weekly to a new flask and supplemented with fresh medium. The purity of three-week old mast cell cultures was established by the following assays.

Histamine assay: $5 \times 10^{4}$ cells were prepared onto a cytospin slide, air dried, fixed in 3\% paraformaldehyde for $10 \mathrm{~min}$, washed, and permeabilized in $0.2 \%$ Triton X-100/ PBS for $2 \mathrm{~min}$. One hundred $\mu \mathrm{l}$ of control rabbit IgG or rabbit anti-histamine at 1:100 dilution (Sigma, ST. Louis, $\mathrm{MO}$ ) were added and the slide was placed in a moist chamber for $2 \mathrm{hr}$. Slides were washed and followed by addition of $100 \mu \mathrm{l}$ of biotinylated oat anti-rabbit IgG at 1:1000 and Texas red-strepavidin at 1:100.

Metachromatic toluidine blue staining: $5 \times 10^{4} \mathrm{BMMC}$ were prepared onto a cytospin slide, air dried, and treated with Mota's fixatives for $10 \mathrm{~min}$, followed by $70 \%$ ethanol. Slides were washed with distilled water and treated with acidic toluidine blue solution for $10 \mathrm{~min}$, followed by $66 \%$ and $100 \%$ ethanol, and finally air-dried and mounted. The magnification was at 200 and 1000 , respectively with $20 \times$ and $100 \times$ objectives

Zymosan ingestion: Less than 1\% of cells in BMMC cultures ingested opsonized zymosan particles, after incubation for $1 \mathrm{hr}$ at a zymosan concentration of $1,600 \mu \mathrm{g} / 10^{6}$ cells, as assessed by Giemsa staining [14], an indication of macrophage contamination.

\section{Purification of BMMC by magnetic beads}

Three-week old BMMC were cultured in 20\% WEHI-3conditioned medium and stimulated with GM-CSF at 100 $\mathrm{U} / \mathrm{ml}$ with or without supplement of IL-4 at $100 \mathrm{U} / \mathrm{ml}$. About $98-99 \%$ of cells were stained positive by toluidine 
blue, and less than $1-2 \%$ of cells were positive by MAbs anti-B220/CD45R (B cells), anti-F4/80 (macrophages/ monocytes) or anti-CD11c (DC). Three week old BMMC at $5 \times 10^{6}$ cells $/ \mathrm{ml}$ in the bulk cultures of $5 \times 10^{8}$ cells, were treated with $2.5 \mu \mathrm{g} / \mathrm{ml}$ anti-B220 and anti-F4/80 followed by mouse anti-rat kappa light chain (MAR18.5) coupled to magnetic MicroBeads ${ }^{\mathrm{Tw}}$ (Miltenyi Biotec) and then passed through anti-CD11c coupled directly to magnetic beads. BMMC undergoing two negative selections were considered pure mast cells. Columns were thoroughly washed, and the adherent cells bound to the beads were harvested.

\section{$\mathrm{BMMC}$ and $\mathrm{APC} / \mathrm{T}$ cell hybridoma cocultures}

To employ as a source of APC, BMMC were primed with recombinant GM-CSF $(100 \mathrm{U} / \mathrm{ml})$ overnight prior to harvest. In some experiments, BMMC were then negatively selected by passing through affinity antibody-coupled magnetic beads as described above, and the optimal ratios of BMMC to T-cells were determined to be from $10^{2}$ to $10^{5}$. Routinely, $1 \times 10^{5} \mathrm{BMMC}$ were incubated with $1 \times 10^{5} \mathrm{~T}$ cell hybridoma cells (restricted for OVA peptide and I-Ad) in the presence of IgE-TNP-OVA complexes, TNP-OVA conjugate, native OVA protein or OVA $323-339$ peptides; or with AD10 T cell line (restricted for PCCP peptide and I-Ek) in the presence of PCCP for 48 to $72 \mathrm{hr}$ for optimal levels of IL-2 production. Alternatively, BMMC $\left(1 \times 10^{5}\right.$ cells $)$ were pulsed with the above antigens overnight, washed, and added to $1 \times 10^{5}$ 3Do-54.8 without further antigen addition. Levels of IL-2 secreted by $3 \mathrm{Do}-54.8$, or AD10 were quantified by a bioassay that measures $\left[{ }^{3} \mathrm{H}\right]$-thymidine incorporation by IL-2-dependent NK-3 cells. Supernatants were routinely harvested after $48 \mathrm{hr}$ of incubation, and IL-2 content was assessed as followed. Thirty $\mu \mathrm{l}$ of supernatant from each sample were added to $10^{4} \mathrm{IL}-2$ dependent NK-3 cells for $48 \mathrm{hr}$. One $\mu \mathrm{Ci}$ of ${ }^{3} \mathrm{H}$-thymidine was added to NK-3 cultures overnight before cell harvest. Incorporation of ${ }^{3} \mathrm{H}$-thymidine was determined by a $\beta$-counter. Data were expressed as means and standard deviations of CPM (counts per minute) of triplicate or quadruplicate 96 well cultures.

\section{Sorting by flow cytometry}

Cells were harvested from three-week old BMMC cultures. Approximately, $20 \times 10^{6}$ cells were harvested from three-week old BMMC cultures, resuspended at $10^{6} / \mathrm{ml}$. Cells were incubated at $4^{\circ} \mathrm{C}$ with $1 \mu \mathrm{g} / \mathrm{ml}$ MAb FITCanti-FceRI $\alpha$ (clone TW, rat MAb IgG, a gift of Dr. David Holowka, Cornell Univ) for $45 \mathrm{~min}$, washed and harvested. Flow cytometric sorting experiments were performed using a FACS III cell sorter (Becton-Dickinson, Sunnyvale, CA). An argon ion laser (Model 164-05, Spectra-Physics) was used at a power of $300 \mathrm{~mW}$ and an excitation wavelength of $488 \mathrm{~nm}$. FITC (green) fluorescence was detected by a combination of a $520 \mathrm{~nm}$ long pass and a $540 \mathrm{~nm}$ short pass filter. Sorting was carried out using standard three-droplet deflection criteria with a $70 \mu \mathrm{m}$ nozzle at the rate of analysis of $\sim 300$ cells/s. About $10 \times$ $10^{6}$ cells were sorted via one continual operation overnight. Sterilization of the tubing system was performed with $70 \%$ ethanol. FceRI $(+)$ cells were then sorted by flow cytometry by a stringent cut-off point into FceR ${ }^{\text {hi }}(2-3$ $\log$ intensity) vs FceRI $I^{\mathrm{lo}}(0-1 \log$ intensity) population. Next, $1 \times 10^{5}$ FceRI $I^{\text {hi }} / \mathrm{MHCII}(+)$ cells or FceRI Io $/$ MHCII() cells were incubated with $10^{5} 3 \mathrm{Do}-54.8 \mathrm{~T}$ cell hybridomas in the presence of different concentrations of IgETNP-OVA, TNP-OVA or IgE (A, B) as well as OVA or OVA peptide (C) for $72 \mathrm{hr}$. Supernatants were then harvested and levels of IL-2 were tested for $\left[{ }^{3} \mathrm{H}\right]$-thymidine incorporation by IL-2-dependent NK-3 cells.

\section{FACS analysis of cell surface and intracellular staining}

For viable cell staining, $1 \times 10^{6}$ cells were resuspended in $100 \mu \mathrm{l}$ medium containing MAbs at $1-2 \mu \mathrm{g} / \mathrm{ml}$ at $4^{\circ} \mathrm{C}$ for $30 \mathrm{~min}$, washed, and fixed with $2 \%$ paraformaldehyde. For two-color staining for FceRI $\alpha$ and surface MHC II, cells were incubated with FITC-anti-FceRI $\alpha(\mathrm{TW})$ and PEanti-IA ${ }^{d}$. For two-color staining for differentiation of mast cells and basophils, three week old BMMC were stained are incubated with FITC anti-FceRI $\alpha(\mathrm{TW})$ and PE-anti-mouse c-kit/CD117 (2B8). For intracellular staining, cells were first fixed in 2\% paraformaldehyde in Dulbecco-PBS (D-PBS) for $20 \mathrm{~min}$ at $4^{\circ} \mathrm{C}$. Cells were then washed twice with permeabilization buffer ( $0.1 \%$ saponin in D-PBS without $\left.\mathrm{Mg}^{2+} / \mathrm{Ca}^{2+}, 1 \% \mathrm{FBS}\right)$, and stained cells with FITC- anti-FceRI $(\mathrm{TW})$ and PE-anti-IAd. FACS analysis was performed on a FACScan (Becton Dickinson). Ten thousand events were collected and analyzed by CELLQuest program (version 1.2.2).

\section{Results}

Pure BMMC depleted of professional APC present antigens and are more efficient via FcERI-mediated antigen uptake

BMMC cultured in IL-3 for three weeks were shown to present antigen (9). It is critical to ascertain whether BMMC cultures contain pure mast cells without contaminating APC cell types. Nearly all the cells in the cultures were mast cells as ascertained by intracellular histamine staining (Fig. 1: Panels b and e vs a and d). Because macrophages that internalize histamine may also be stained positive [15], the ubiquitous presence of abundant metachromatic granules characteristic of mast cells, was then ascertained by toluidine blue staining (Fig. 1: Panels $c$ and $f$ ).

Fig. 1g showed that $98.7 \%$ of BMMC $(90.84 \%$ in the third quadrant plus $7.85 \%$ in the second quadrant, Fig. 1 : Panel g) exhibited surface receptors for stem cell factor (c-kit, CD117), indicating these cells are of the mast cell 

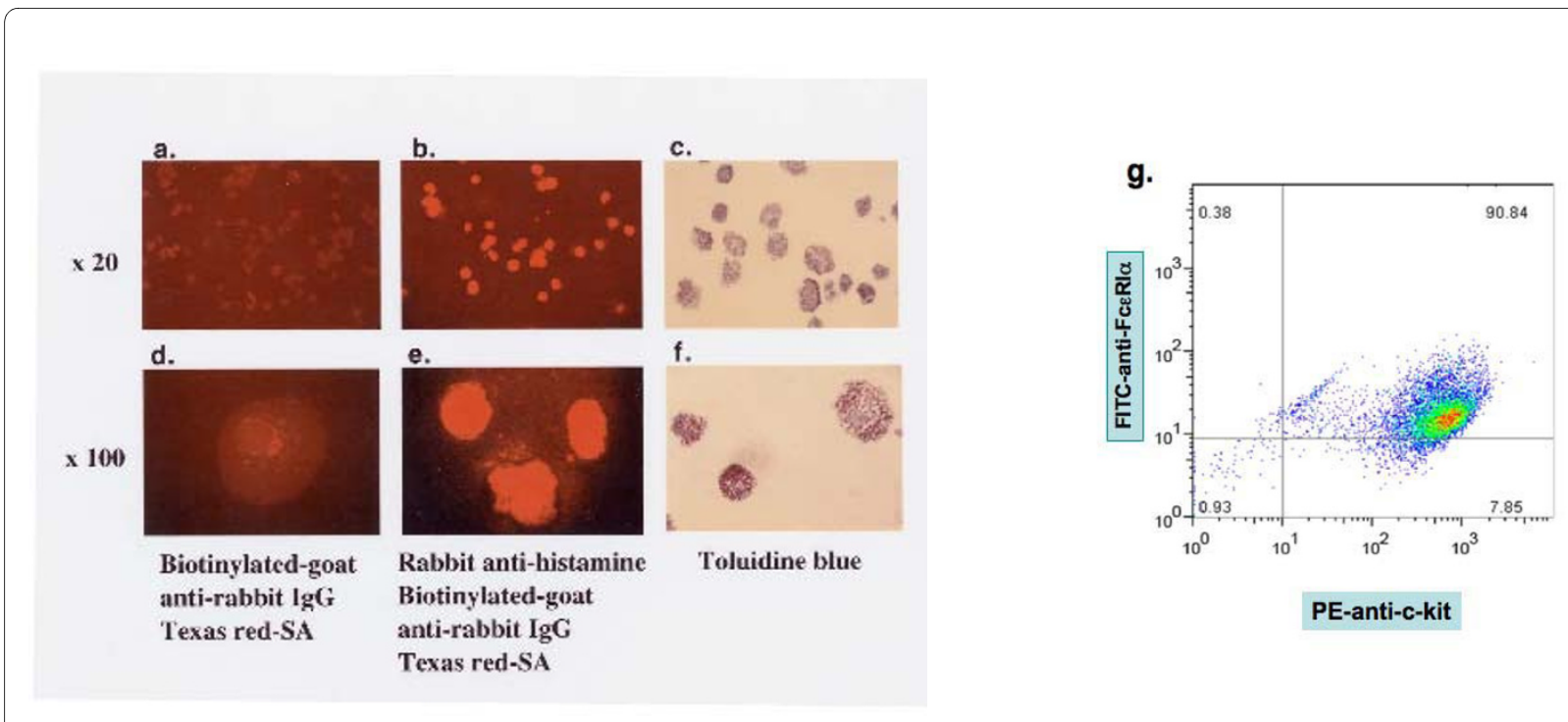

Figure 1 Characterization of three-week old BMMC cultures. Histamine staining: slides treated with rabbit IgG (Panel a, d) vs rabbit anti-histamine (Panel b, e). Toluidine blue staining: $5 \times 10^{4} \mathrm{BMMC}$ were prepared onto a cytospin slide, examined respectively with $20 \times($ Panel c) and $100 \times$ objectives (Panel f). Surface FcERl and c-kit expression: BMMC were stained with PE-anti-c-kit and FITC-anti-FceRl analyzed by flow cytometry. Numerically, $98.7 \%$ c-kit + cells are mast cells, including c-kit +, FceRlhi cells (quadrant 3, 90.84\%), and c-kit +, FceRllo cells (quadrant 2, 7.85\%) (g). The procedures were described in Materials and methods.

and not basophil lineage, and apparently all surface c-kit + BMMC also exhibited surface high affinity IgE Fc receptors delineated by two color FACS (Fig. 1: Panel g). It was previously reported that a minor subset of FceRI + mast cells, exhibiting surface c-kit, exists in IL-3/SCF containing bone marrow cultures [16]. Thus $0.38 \%$ cells (of the fourth quadrant) exhibiting surface FceRI but not c-kit, may either belong to the putative basophils or to an early lineage mast cells.

Due to the presence of approximately $1 \%$ residual cells devoid of mast cell markers, we therefore proceeded to determine whether purified BMMC, negatively selected by adsorption on MACS columns with anti-B220, antiF4/80 and anti-CD11c, can still present antigens.

As shown in Fig. 2A, pure mast cells, depleted of contaminating B-cells, monocytes, and dendritic cells were fully capable of antigen presentation. Mast cells treated with IgE-TNP-OVA complexes were more effective in antigen presentation than those treated with TNP-OVA alone. Approximately four-fold enhancement of ${ }^{3} \mathrm{H}$-thymidine incorporation was observed with mast cells treated with $0.1 \mu \mathrm{g} / \mathrm{ml} \mathrm{IgE-TNP-OVA}$ as compared to those treated with similar dose of TNP-OVA. Moreover, close to two-fold enhanced ${ }^{3} \mathrm{H}$-thymidine uptake was observed in mast cells treated with $1 \mu \mathrm{g} / \mathrm{ml}$ IgE-TNPOVA as compared to those treated with TNP-OVA, while the difference in efficacies of presenting IgE complexes vs haptenated antigen alone, was not noticeable in higher dose range from 10 to $100 \mu \mathrm{g} / \mathrm{ml}$. Purified BMMC were also able to process and present native OVA as well as present OVA peptide to T cells (Fig. 2B and Fig. 2C). On the other hand, mast cells were inefficient in presenting antigens at levels from 0.001 to $0.01 \mu \mathrm{g} / \mathrm{ml}$ (not shown).

Next, to prove the less than $1 \%$ contaminating cells were indeed effectively removed, adherent cells, physically separated from pure mast cells, eluted from MACS columns in the same experiment of these bulk cultures, were then examined for APC function. As shown in Fig. 2D and Fig. 2E, B cells/macrophages and dendritic cells were potent in presenting different forms of antigens. And as anticipated, similar efficacy of antigen presentation was observed in these contaminating APC, treated with IgE antigen complexes vs haptenated antigens, indicating FceRI-mediated antigen focusing did not play a role in these professional cell types. Taken together, these experiments showed that residual contaminating APC exhibiting the respective APC surface markers and APC function, were indeed effectively removed from the three-week BMMC cultures; and that mast cells, even purer than the starting highly pure c-kit + mast cells, were still fully capable of antigen presentation in the absence of contaminating APC.

Next, we evaluated efficacies of antigen presentation at a more extensive titration of mast cells to T-cell ratios as compared to contaminating professional APC, recovered from the MACS columns, on a cell-to-cell basis. As shown in Fig. 2F, significant T-cell responses were stimulated by all three types of cells, B-cells/monocytes, DC and mast cells from a range of $1 \times 10^{5}$ to $2.5 \times 10^{2}$, added to $1 \times 10^{5} \mathrm{~T}$-cell hybridomas, i.e., at APC to T-cell ratios 

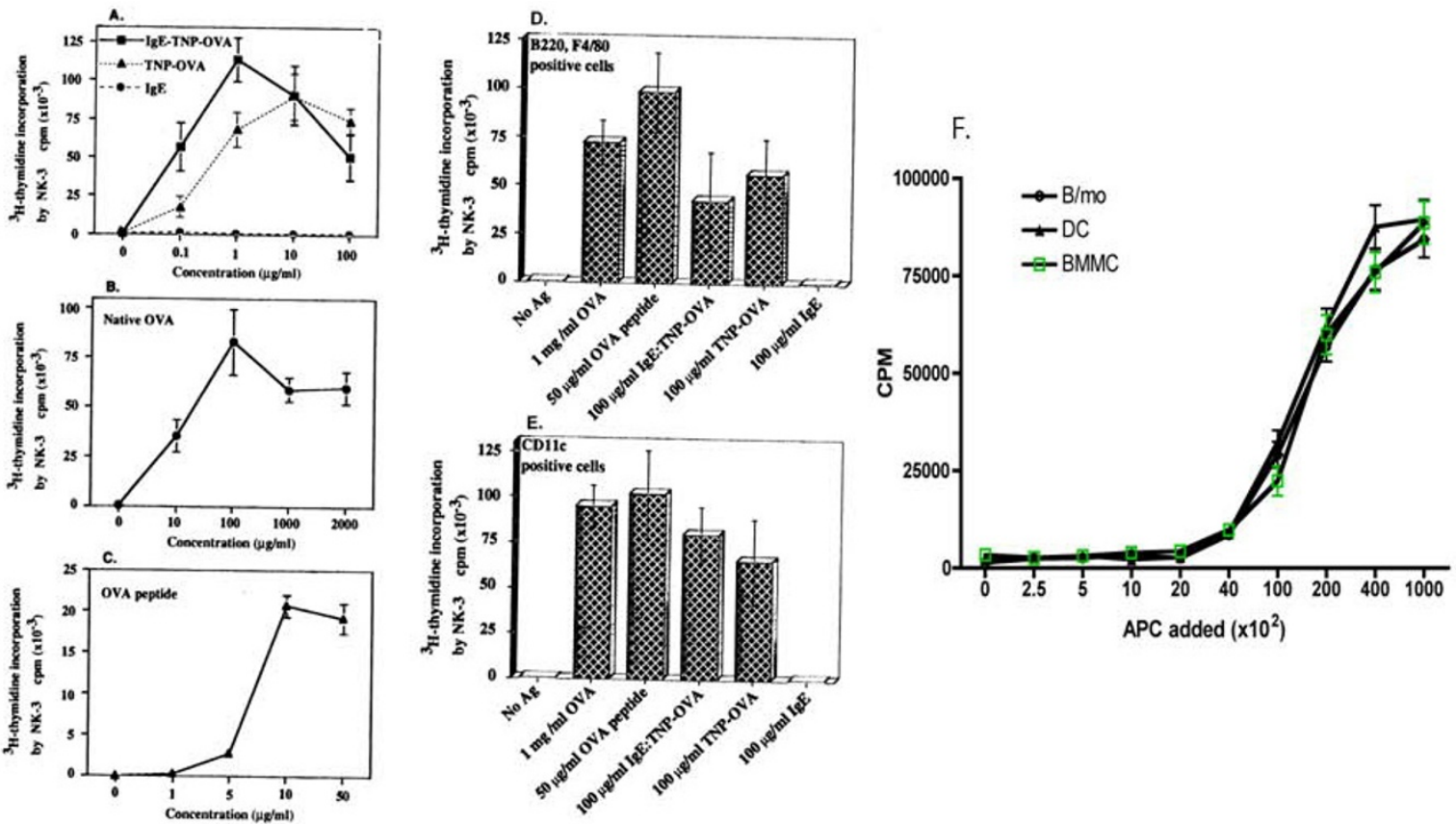

Figure 2 BMMC cultures depleted of contaminating APC were fully capable of antigen presentation. $1 \times 10^{5}$ pure BMMC depleted of B cells/ macrophages or DC were incubated for 72 hr with $10^{5}$ 3Do- 54.8 in the presence of IgE-TNP-OVA, TNP-OVA (Panel A), OVA (Panel B) or OVA peptide (Panel C). The residual contaminating APC eluted from the anti-B220/F480 and CD11C MACS columns from bulk cultures $\left(\sim 2 \times 10^{8}\right.$ cells in order to harvest around $1 \%$ contaminating cells for experiments), were prepared. $0.4 \times 10^{5} \mathrm{~B}$ cells/macrophages (Panel D) or $0.4 \times 10^{5} \mathrm{DC}($ Panel E) were incubated for $72 \mathrm{hr}$ with $10^{5}$ 3Do-54.8 in the presence of IgE-TNP-OVA, TNP-OVA, OVA, or OVA peptide. Next, in the titration experiment, pure mast cells were similarly prepared as above by MACD columns, along with column eluted, residual contaminating APC of these bulk cultures. The different cell types were then incubated with 105 3Do-54.8 in the presence of OVA peptide, at a APC to T-cell ratios ranged from 1:1 to 0.0025:1 at a serial 2- to 2.5fold dilutions (Panel F). Levels of IL-2 in 72 hr supernatants were determined by stimulating ${ }^{3} \mathrm{H}$-thymidine incorporation and proliferation of IL-2 dependent NK-3 cells as described in Material and methods.

from 1:1 to 0.0025:1. Quantitative CPM reduction was proportional to the number of input APC and T-cell ratios from 1:1 to $0.2: 1$. In contrast, CPM incorporation was diminished impressively at the 'inflexion' point noticed at $4 \times 10^{3}$ input APC to T-cell ratio at 0.1:1. Furthermore, precipitous fall in CPM counts around background levels was noticed at $2 \times 10^{3}$ input APC to T-cell ratio at $0.04: 1$. Because a typical in vitro BMMC culture set at 1:1 APC to T-cell ratio, the contaminating APC, when present, fell below $10^{3}$ per culture, the possibility of contaminating APC henceforth was responsible for antigen presentation in the three week old BMMC cultures, can be formally ruled out.

Thus the above data show four pertinent points for mast cells as APC: (i) pure mast cells were indeed capable of antigen presentation; (ii) pure mast cells were equally potent APC as compared to professional APC: B-cells/ monocytes and DC; (iii) it is unlikely that contaminating cells at $\sim 1 \%$ levels in the three week BMMC were responsible solely for antigen presenting capacity; (iv) it also follows that it is unlikely that the $0.38 \%$ surface FceRI +/c-kit negative cell subset, even if they represent the basophils, can not be responsible for antigen presentation in the BMMC cultures.

Augmented antigen presentation via IgE-antigen complexes, as shown in the above Fig. 2A, suggests an important role of IgE-dependent antigen presentation via FceRI-mediated pathway. To block FceRI receptor-mediated antigen presentation, BMMC were preincubated with anti-ragweed IgE at $100 \mu \mathrm{g} / \mathrm{ml}$ for one $\mathrm{hr}$ at $37^{\circ} \mathrm{C}$ prior to addition of IgE-TNP-OVA at $1 \mu \mathrm{g} / \mathrm{ml}$. Fig. 3 showed that the capacity of IgE-TNP-OVA-treated mast cells to stimulate $T$ cells was significantly reduced after treatment with anti-ragweed IgE. These results support the notion that FceRI on BMMC plays an important role in antigen presentation.

\section{FceR/hi but not FceRIlo subset of three-week old BMMC is capable of MHC II-mediated antigen presentation}

The augmented antigen-presenting pathway via FceRI prompted the hypothesis that the BMMC subset expressing high levels of FceRI (i.e., mean fluorescence intensity of two to three logs by flow cytometry) may also express 


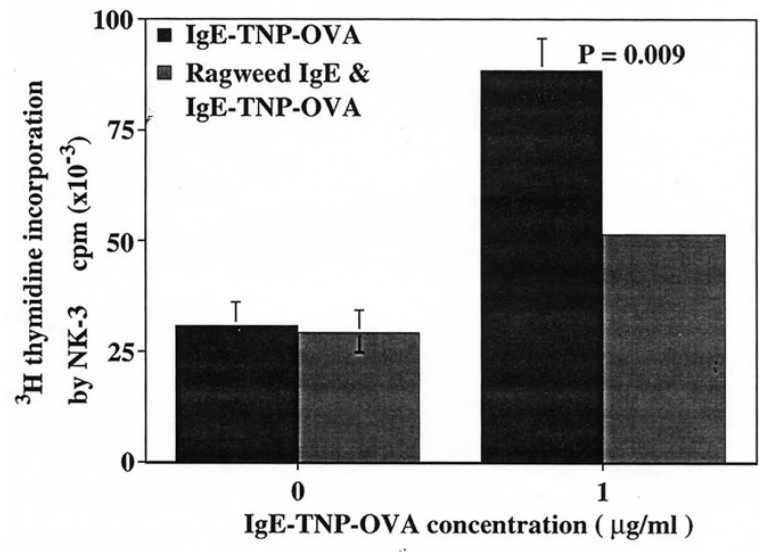

Figure 3 Block of surface FceRl-mediated antigen focusing and presentation of anti-DNP IgE/TNP-OVA by ragweed-specific lgE. BMMC were preincubated with anti-ragweed lgE at $100 \mu \mathrm{g} / \mathrm{ml}$ for one $\mathrm{hr}$, washed and, followed by addition of IgE/TNP-OVA complexes, and coincubated with 3Do-54.8. Levels of IL-2 in $72 \mathrm{hr}$ supernatants were determined by stimulating ${ }^{3} \mathrm{H}$-thymidine incorporation and proliferation of IL-2 dependent NK-3 cells as described in Material and methods.

high levels of cell surface MHC II. As shown in Fig. 4A, one subset of FceRI ${ }^{\text {hi }}$ subset of BMMC exhibited high levels of cell surface FceRI and MHC II; this subset of FceRI/ MHC II high cells was delineated in quadrant 3 (35\%), and $4 \mathrm{~b}(13.5 \%)$ with a subtotal of $48.5 \%$ pure mast cells. Moreover, the FceRI ${ }^{l o}$ subset exhibited lower but significant level of cell surface FceRI, devoid of surface MHC II, i.e., FceRIlo/MHC II(-) cells, delineated in quadrant 1a and $1 \mathrm{~b}$ with a subtotal of $50.8 \%$. Therefore, FceRI ${ }^{\text {hi }}$ and FceR $I^{\text {lo }}$ constituted approximately $99 \%$ mast cells with or without expressing surface MHC II. Only 0.6\% Fc\&RI ${ }^{\text {hi }}$ cells exhibited low levels of surface MHCII in quadrant 2, and very few $(\sim 0.01 \%)$ FceRIlo cells exhibited high level surface MHC II.

In striking contrast, Fig. 4B showed that despite the differential expression of cell surface FceRI and MHC II between these two distinct subsets of mast cells, almost all BMMC exhibited high levels of intracellular FceRI, indicating their mast cell lineage. Interestingly, in contrast to cell surface expression, nearly all mast cells exhibited intracellular MHC II, while $87 \%$ of the mast cells exhibited high levels of intracellular MHC II with 12\% mast cells exhibiting lower level of MHC II. Furthermore, as anticipated, surface FceRI ${ }^{\mathrm{hi}} / \mathrm{MHC}$ II + mast cell subset, compared to surface FceRI ${ }^{\mathrm{lo}} / \mathrm{MHC}$ II(-) subset, exhibited higher levels of adhesion molecules, LFA- $1 \alpha$, ICAM-1, and $\alpha 4$ integrin and $\beta 1$ integrin (data not shown).

In summary, the above data demonstrated two points: (i) ubiquitous expression of the FceRI marker of the receptor $\alpha$ chain (detected by MAb TW) intracellularly ascertained the mast cell lineage of BMMC culture; (ii) distinction of mast cell subsets is made according to differential surface expression but not intracellular expression of the two employed markers, FceRI and MHC II.

The aforementioned observations then prompt the hypothesis that subset of FceRI ${ }^{\text {hi }}$ mast cells, expressing high levels of MHC II, is competent in antigen presenta-
A. Cell surface staining

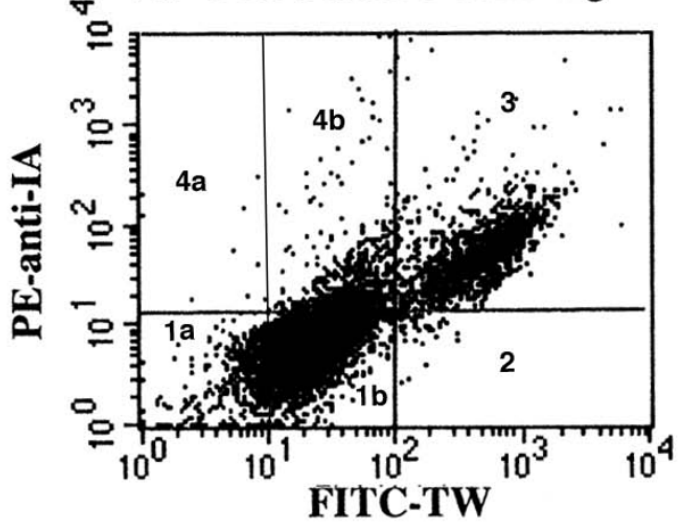

B. Intracellular staining

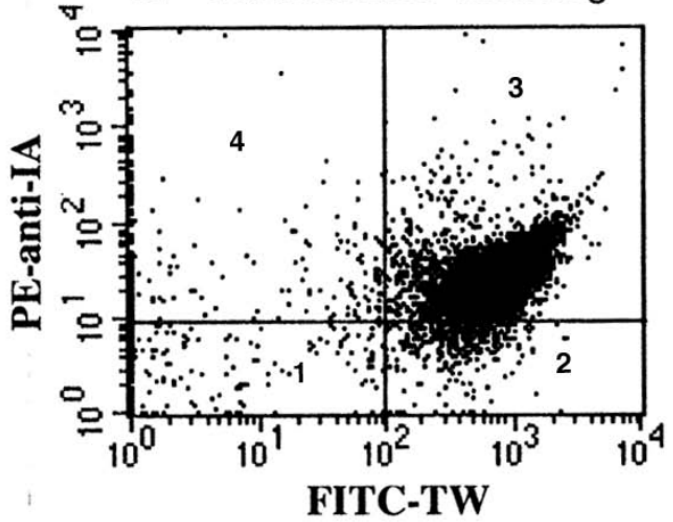

Figure 4 Delineation of surface vs intracellular FcERI/surface MHC II+ cells in three-week old BMMC. For viable cell staining, $1 \times 10^{6}$ three-week old mast cells were stained with FITC-anti-FceRla (TW) and PE-anti-IAd at $10 \mu \mathrm{g} / \mathrm{ml}$ and fixed with $1 \%$ paraformaldehyde. Panel A: FceRI + cells were

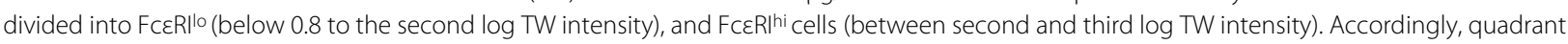
\#2 (.6\%), \#3 (35\%) and \#4b (13.5\%) amounted to 49.1\% FcER/hi cells. By contrast, quadrant 1a (9.8\%) and \#1b (41\%) amounted to 49.8\% FcERIlo cells. In total, $99 \%$ cells were FcERI + cells. Panel B: To determine intracellular distribution, cells were prefixed, permeabilized, and stained. Quadrant percentages were: quadrant \#1 (.5\%), \#2 (12\%), \#3 (87\%), and \#4 (0.5\%). Approximately 99\% cells were FcERIhi mast cells, and $87 \%$ of these mast cells also exhibited high levels of intracellular MHC II. 
tion, while subset of FceR $I^{\mathrm{lo}}$ mast cells, lacking cell surface MHC II, is incapable of antigen presentation. Next, BMMC were differentially sorted into the surface FceRI ${ }^{\text {hi }}$ vs. the FceRI ${ }^{\text {lo }}$ subset according to the surface intensity by MAb anti-FceRI $\alpha(T W)$. Sorted surface FceRI ${ }^{\text {hi }}$ subset of BMMC was capable of presenting all three form of antigens (Fig. 5), and as anticipated, this subset of BMMC was more efficient in presenting IgE-TNP-OVA as compared to haptenated OVA, native OVA (Fig. 5A) and peptide antigen (Fig. 5C). In contrast, purified surface FceRI ${ }^{\text {lo }}$ subset, also lacking surface expression of MHCII, was incapable of presenting IgE-TNP-OVA (Fig. 5A), TNPOVA (Fig. 5B), and OVA peptide (Fig. 5C). It is pertinent to point out that the contaminating residual APC that do not express FceRI, should have been enriched in the FceRI ${ }^{\text {lo }}$ subset. Thus, the conspicuous absence of antigenpresentation function in this BMMC subset indicates and substantiated the fact that the contaminating APC can not account for antigen presentation in BMMC/T-cell hybridoma cocultures.

Consequently, we tested whether blocking surface MHC II of the FceRI ${ }^{\text {hi }}$ antigen-presenting BMMC subset inhibited antigen presentation. As shown in Fig. 6, addition of MAb anti-IAd profoundly inhibited IgE-dependent antigen presentation at 1 to $100 \mu \mathrm{g} / \mathrm{ml}$ IgE-TNPOVA (Fig. 6A). Treatment with anti-IAd also potently diminished antigen presentation of both native OVA protein and OVA peptide (Fig. 6B and Fig. 6C). In contrast, $\mathrm{MAb}$ against an irrelevant specificity, i.e., anti-IEk $(17-3-$ 3) did not affect the antigen presenting function of BMMC (not shown).

\section{The antigen-presenting function of BMMC is diminished upon extended culture}

Next we examined whether 4 to 6 week-old BMMC (DBA/2 mice, $\mathrm{H}-2^{\mathrm{d}}$ ) can also present antigen Surprisingly, as shown in Table A1A, IL-3 cultured, 4-week old BMMC were incapable of presenting OVA, TNP-OVA, and the OVA peptide. The source of the IL-3 as growth factors did not make a difference, since BMMC cultured in the presence of IL-3-containing conditioned medium from D11 cells, recombinant IL-3 $(100 \mathrm{U} / \mathrm{ml})$, primed with GM-CSF all lacked antigen-presenting capacity. Under physiological conditions, stem cell factor (SCF) stimulates mast cell progenitors of various tissue origins to differentiate more toward a mature phenotype of connective tissue mast cells [5-7]. As shown in Table A1A, BMMC cultured with SCF $(1 \mu \mathrm{g} / \mathrm{ml})$ or a combination of SCF and IL-3 still failed to present antigen. Moreover, BMMC treated further with IL-4 $(100 \mathrm{U} / \mathrm{ml})$ [9] did not render four-week old BMMC competent in antigen presentation. In contrast, three-week old BMMC as positive control were consistently capable of presenting different forms of antigens regardless supplementation of IL-3 or SCF or priming by IL-4. Furthermore, four-week old BMMC prepared from another $\mathrm{H}-2^{\mathrm{d}}$ haplotype, BALB/c mice, were likewise not capable of antigen presentation (data not shown).

We then extended the study to APC function of BMMC prepared from B10.BR mice $\left(\mathrm{H}-2^{\mathrm{k}}\right)$ of a different $\mathrm{MHC}$ haplotype. As also shown in Table A1A, four-week old BMMC failed to present PCC, TNP-PCC, and IgE-TNPPCC to PCCP-specific AD10 T-cell line [17]. Moreover, these $\mathrm{BMMC}$ were not rendered competent in antigen presentation by additional IL-4 treatment [18]. The lack of antigen-presenting function by 4-6 weeks old pure $\mathrm{BMMC}$ was consistently observed in fifteen experiments over 12 months. Moreover, Table B1B showed that the loss of antigen-presenting function occurred precipitously in the midst between the third and fourth weeks on day 26 in the same cultures. The loss of antigen presenting function was not due to loss of adherent cell population since media were not decanted nor the cells transferred to a new dish. These observations indicate a unique temporally restricted antigen-presenting capacity inherent in bone marrow derived mast cells. In contrast, the antigen-presenting function of the purified residual professional APC were fully functional throughout the entire 3 -week 3 to 6 -week cultures (not shown).

\section{Discussion}

Herein, the study shows that highly pure mast cells from three week old, IL-3-containing bone marrow cell cultures indeed present antigens after depletion of $\sim 1 \%$ contaminating APC. This study also provides the novel observations: (i) two subsets of BMMC are delineated; one subset expressing both surface high levels of FceRI and high surface MHC II, while another expressing low levels of surface FceRI with non-detectable levels of surface MHC II. Nevertheless, the intracellular expression of both biomarkers are equivalent in all BMMC; (ii) the purified FceRIhi BMMC subset that express high levels of surface MHC II, is competent in antigen presentation, while the FceRI ${ }^{\text {lo }}$ subset can not present antigens. Since FceR $I^{\text {lo }}$ was presumably enriched even 2 -fold for the putative contaminating APC, its conspicuous lack of capacity for antigen presentation strongly argues against the role of contaminating professional APC for stimulating T-cell hybridomas in BMMC/T-cell cocultures; (iii) augmented IgE-dependent antigen presentation pathway in the FceR $I^{\text {hi }}$ subset is inhibited by IgE of a different specificity, and the APC function is blocked by anti-MHC II antibodies; (iv) the APC function is also temporarily restricted to the three weeks old BMMC, and is irrevocably lost in further extended cultures.

Previously, Mecheri and colleagues showed BMMC cultured in ConA-conditioned media or two-way mixed lymphocyte reaction (MLR) supernatant present antigens 


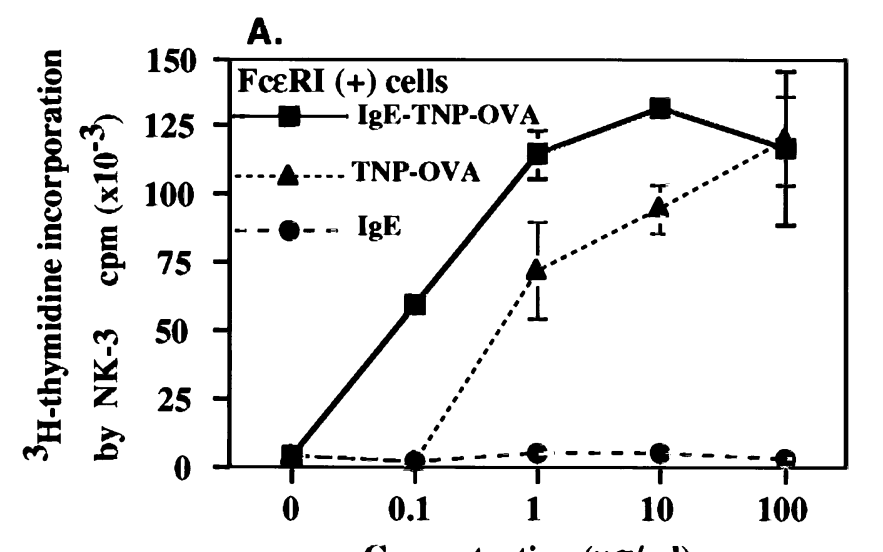

B.
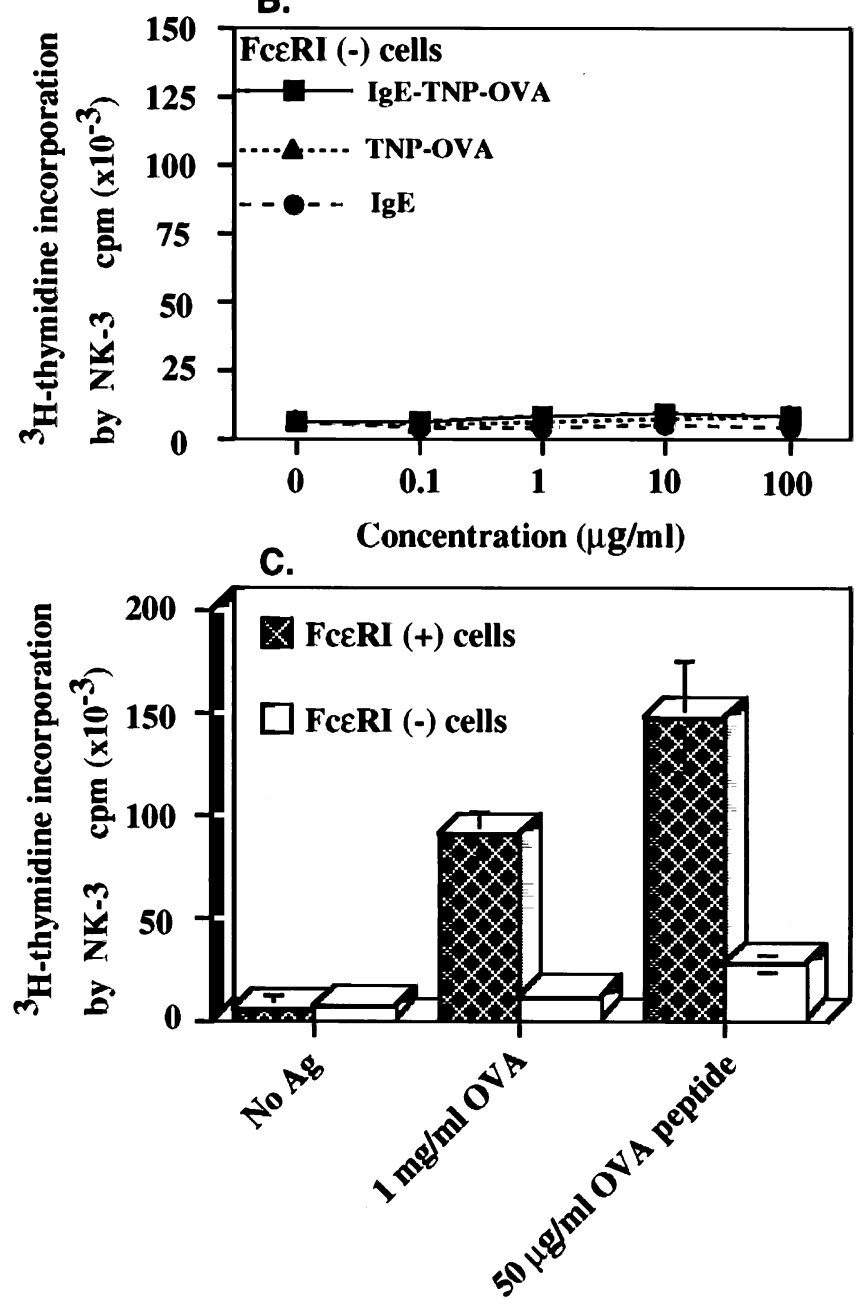

Figure 5 Surface FceRI hi/MHCII(+) BMMC but not surface FceRIlo/MHCII(-) BMMC are capable of presenting antigens. Three-week old BMMC

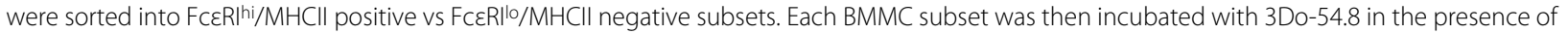
IgE-TNP-OVA (Panel A), TNP-OVA (Panel B) and OVA peptide (Panel C), and levels of IL-2 in 72 hr supernatants were determined by stimulating ${ }^{3} \mathrm{H}-$ thymidine incorporation and proliferation of IL-2 dependent NK-3 cells as described in Material and methods. 

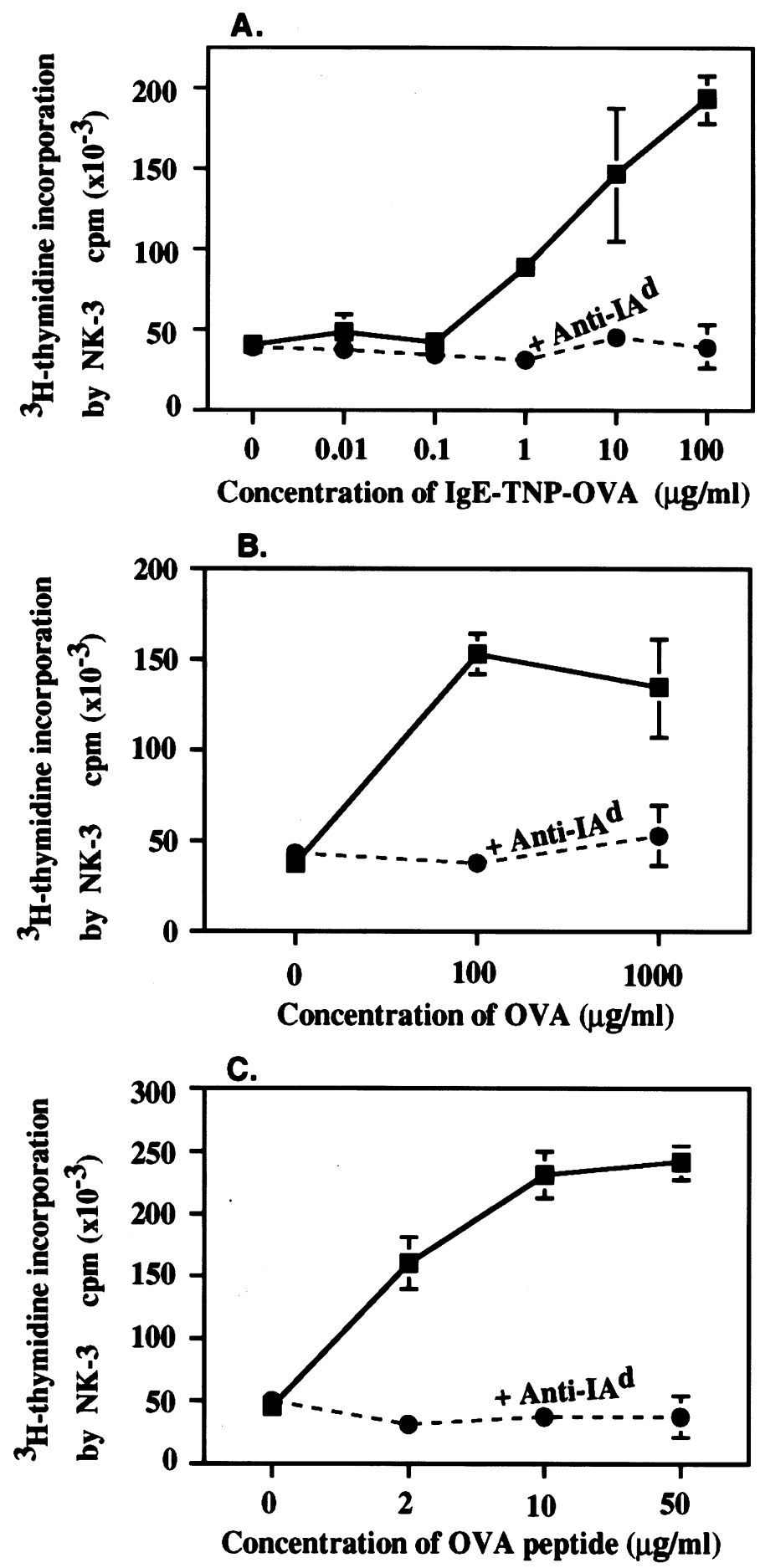

Figure 6 Anti-IAd potently inhibits antigen presentation by BMMC (H-2 $\left.\mathbf{2}^{\mathrm{d}}\right) .10^{6} \mathrm{BMMC}$ were treated with $10 \mu \mathrm{gg} / \mathrm{ml} \mathrm{MAb}$ anti-IAd for $30 \mathrm{~min}$ at $4^{\circ} \mathrm{C}$. $10^{5}$ treated BMMC were then incubated with $1 \times 10^{5}$ 3Do 54.8 in the presence of IgE-TNP-OVA (Panel A), OVA (Panel B) and OVA peptide (Panel C). Levels of IL-2 in $72 \mathrm{hr}$ supernatants were determined by stimulating ${ }^{3} \mathrm{H}$-thymidine incorporation and proliferation of IL-2 dependent NK-3 cells as described in Material and methods. 
Table 1: A - Three-week but not four-week old BMMC are capable of antigen presentation and B - Loss of APC function between three and four week old BMMC

A

DBA/2 (H-2d) Culture conditions

Antigenic stimulation (SI) 3Do-54.8

Background (CPM)

\begin{tabular}{|c|c|c|c|c|c|}
\hline 4 week old & BMMC, GM-CSF primed & OVA & OVAp & IgE-TNP-OVA & None \\
\hline & WEHI-3 & 0.74 & 1.1 & .95 & 1,504 \\
\hline & D11 sup & .86 & .76 & .58 & 2,045 \\
\hline & Rec IL-3 & .75 & .80 & .63 & 1,786 \\
\hline & SCF & 1.3 & .67 & .75 & 1,745 \\
\hline & WEHI-3+SCF & .95 & .87 & 1.0 & 3,164 \\
\hline & WEHI-3+IL-4 & .79 & .83 & .87 & 2,568 \\
\hline \multirow[t]{4}{*}{3 week old } & BMMC, GM-CSF primed & & & & \\
\hline & WEHI-3 & $7.8^{*}$ & $8.5^{*}$ & $14.4^{*}$ & 2,359 \\
\hline & SCF & $10.5^{*}$ & $9.6^{*}$ & $15.2^{*}$ & 2,790 \\
\hline & WEHI-3+IL-4 & $8.5^{*}$ & $7.4^{*}$ & $22.3^{*}$ & 3,876 \\
\hline B10.BR (H-2k) & & $\begin{array}{l}\text { Antigenic stimulation (SI) } \\
\text { AD10 }\end{array}$ & & & \\
\hline \multirow[t]{3}{*}{4 week old } & BMMC GM-CSF primed & PCC & PCCP & IgE-TNP-PCC & \\
\hline & WEHI-3 sup & 1.4 & 1.3 & 0.8 & 2,140 \\
\hline & $+\mathrm{IL}-4$ & 1.2 & 1.3 & .9 & 1,398 \\
\hline
\end{tabular}


Table 1: A - Three-week but not four-week old BMMC are capable of antigen presentation and B - Loss of APC function between three and four week old BMMC (Continued)

\begin{tabular}{|c|c|c|c|}
\hline $\mathrm{DBA} / 2\left(\mathrm{H}-2^{\mathrm{d}}\right)$ & Culture conditions & $\begin{array}{l}\text { Antigenic stimulation (SI) } \\
\text { 3Do-54.8 }\end{array}$ & Background (CPM) \\
\hline $\begin{array}{l}\text { Days old of } \\
\text { BMMC }\end{array}$ & $\begin{array}{l}\text { GM-CSF primed, in WEHI-3 } \\
\text { media }\end{array}$ & IgE-TNP-OVA & None \\
\hline Day 22 & ibid. & $10.8^{*}$ & 1,799 \\
\hline Day 23 & ibid. & $12.1^{*}$ & 1,325 \\
\hline Day 24 & ibid. & $14.5^{*}$ & 2,569 \\
\hline Day 25 & ibid. & $12.6^{*}$ & 1,634 \\
\hline Day 26 & ibid. & $3.3^{*}$ & 2,788 \\
\hline Day 27 & ibid. & 0.86 & 2,961 \\
\hline \multicolumn{4}{|c|}{$\begin{array}{l}\text { 1A: BMMC (H-2d, or H-2k) were prepared by culturing bone marrow cells in the presence of different sources of IL-3 ( } 20 \% \text { supernate) or SCF }(1 \mu \mathrm{g} / \\
\text { ml) for three or four weeks with weekly decanting of adherent cells. BMMC were primed with GM-CSF (100 U/ml) for } 48 \mathrm{hr} \text { and some cultures in } \\
\text { addition treated with IL-4 at } 100 \mathrm{U} / \mathrm{ml} \text {. BMMC }\left(\mathrm{H}-2^{\mathrm{k}}\right) \text { and PCCP-specific AD10 T-cell line were stimulated with pigeon cytochrome C (PCC), PCC } \\
\text { peptide (PCCP) or IgE-TNP-PCC complexes at } 10 \mu \mathrm{g} / \mathrm{ml} \text { for } 48 \mathrm{hr} \text { and IL-2 production was determined. } 1 \mathrm{~B} \text { : For daily assessment of APC function } \\
\text { from day } 22 \text { to day } 27 \text { of the fourth week, nonadherent BMMC were directly obtained from the WEHI-3 supplemented culture wares in the fourth } \\
\text { week culture (Day } 22 \text { to Day } 27) \text { without culture media or plate change. Background CPM was determined in cocultures of differently-treated } \\
\text { BMMC plus T cells without antigen stimulation. Stimulation index (SI) was computed as quotients of total CPM of }{ }^{3} \mathrm{H} \text {-thymidine uptake of the } \\
\text { antigen-stimulated cultures over nonantigen-stimulated controls. Triplicates were set for each group of stimulation and the non-stimulated } \\
\text { control, and the means and SE were computed and two-tailed t-test of the antigen-stimulated group compared to background CPM was } \\
\text { performed; SE of all observations were calculated within } 15 \% \text { of the computed means. To simplify data, SI with p values }<0.01 \text { was denoted as a } \\
{ }^{*} \text { marks in cocultures with competent BMMC stimulation. SI of the group without the mark indicated a failure or loss of antigen presentation by } \\
\text { extended cultured mast cells. L-2 secreted in the coculture supernatants was determined by stimulating proliferation and }{ }^{3} \mathrm{H} \text {-thymidine uptake } \\
\text { of IL-2 dependent NK3 cell line. }\end{array}$} \\
\hline
\end{tabular}

to stimulate CD4 + helper T cells $[9,19]$. However, there has been continual debate concerning the purity of BMMC and the role of possible contaminating APC. Our previous study in collaboration with Stevens, Austen and colleagues $[14,20]$ also showed three-week old BMMC grown in WEHI-3-conditioned media were authentic mast cells by EM studies, granular content, as well as release of histamine, PDG2 and leukotrienes via IgEmediated cell activation. The present study also confirms the granularity and histamine content in almost all the cells in three-week old BMMC cultures. Approximately 98.7\% BMMC expressed high density of c-kit and high vs low density of surface FceRI (Fig. 1g and Fig. 4A), and nearly all these BMMC uniformly exhibited high levels of FceRI $\alpha$ in the cytosol (Fig. 4B).

Basophils, present in less than $1 \%$ circulating leukocytes were recently shown to play a critical role in innate immunity and especially in orchestrating Th2 commitment [21]. Although the present culture system did not support basophils, a possible low contamination $(\sim 0.38 \%)$ can not be excluded [16]. Since antibodies to CD200R3
(Ba91 and Ba103) directly activate degranulation of basophils as well as mast cells in vitro [21-24], these antibodies may not be directly employed for depleting minor contaminating basophils in BMMC cultures without a concomitant modulatory effect on antigen presentation by mast cells. On the other hand, these antibodies appeared to eliminate preferentially basophils in vivo. Thus, future studies may be conducted in vivo for evaluating antigen-presenting function of adoptive transferred BMMC, while preferentially depleting basophils in situ in an appropriate animal model deficient in mast cells as well as all the other professional APC cell types. This study also relies on supply of a large quantity of antibodies produced by hybridoma clones, available to the research laboratory [21-24].

Herein, we formally showed that physically purified, surface FceRIhi but not the cell surface FceRIlo (or null) BMMC subset present antigens. Noteworthily, these sorted surface FceRIlo BMMC are also authentic mast cells according to the abundant expression of the lineagespecific FceRI $\alpha$ marker in the cytosol $[25,26]$ (Fig. 4B) and 
surface c-kit (Fig. 1g) [16]. Residual contaminating professional APC did not play a role in these BMMC cultures for three reasons: (i) three week old BMMC depleted of contaminating APC were fully capable of antigen presentation (Fig. 2A-C); (ii) surface FceRI ${ }^{l o}$ BMMC, presumably enriched for the putative professional APC, were not capable of antigen presentation; (iii) purified professional APC added to T-cells at a simulated ratio of BMMC/Tcell cultures, i.e., $10^{3}$ contaminating APC to $10^{5} \mathrm{~T}$-cells, failed to stimulate IL-2 production by T-cell hybridomas (Fig.

Augmented presentation of antigen-IgE complexes can be mediated via the low affinity FceRII pathway [27]. Herein augmented presentation of antigen-IgE complexes was mediated via the high affinity FceRI pathway, blocked by preincubation with monomeric ragweed-specific IgE. Mast cells are increasingly known for downregulating a variety of immune effector functions in skin graft rejection, protozoan infection and UVB-induced contact dermatitis [28-30]. In addition to the straightforward receptor blockade mechanism, the diminished antigen presentation may be in part explained by suppression of APC function due to receptor interactions with monomeric ragweed-specific IgE in contrast to multivalent interactions with TNP-OVA-IgE.

It is not known why low levels of cell surface FceRI $\alpha$ correlated with lack of MHC II cell surface expression (Fig. 4A). MIIC-like compartments were noted intracellularly in mast cells [31]. It is possible that there exists a special mechanism, co-transporting intracellular pools of FceRI and peptides/MHC II in the MIIC-like compartment to the cell surface [31]. Alternatively, the lack of cell surface expression of the alpha subunit of FceRI may be due to lack of intracellular expression of $\beta / \gamma$ subunits $[25,26]$, while surface MHC II expression depends on vesicular transport of MIIC compartments to cell surface during BMMC differentiation. Since exosomes secreted by $\mathrm{RBL}-2 \mathrm{H} 3$ can arm professional antigen presenting cells $[31,32]$, it remains possible that the FceR ${ }^{10}$ mast cell subset may indirectly contribute to antigen presentation via cross-presentation of secreted exosomes by other professional APC [32,33].

The mechanisms for sudden collapse of APC function of BMMC on day $26 \mathrm{BMMC}$ and further extended cell cultures of 4-6 week in vitro, are not unknown. Many possibilities exist. It is interesting to speculate that contaminating basophils and/or professional APC from $\sim 400$ cells to 1,000 cells in the APC/T-cell cocultures may play an indirect role in modulating competence of mast cells in antigen presentation; and starvation of one or both cell types in extended cultures may account for the temporally restricted nature of mast cells as a facultative APC $[28,34]$. The elucidation of cellular and molecular mechanisms underlying the spatiotemporally restricted nature of pure mast cells as APC, remains a future challenge for basic mast cell research and its clinical application.

\section{Conclusions}

Mast cells are increasingly known for modulating a variety of immune effector functions in skin graft rejection, protozoan infection and UVB-induced contact dermatitis [28-30]. The observation herein provides an additional link for integrating inflammatory responses with spatiotemporally restricted antigen presenting function via IgE-dependent antigen presentation pathway in this unique FceR ${ }^{\text {hi }} / \mathrm{MHC} \mathrm{II}^{+}$BMMC subset. Coupling antigen presentation with secretory function of mast cells via the interplay of cell surface FceRI and MHC II can contribute to important pathophysiological responses in both innate and acquired immunity of the host $[24,28,34,35]$.

\section{Abbreviations}

APC: Antigen-presenting cells; BMMC: Bone marrow-derived mast cells; DC: Dendritic cells; FcERI: Type I high affinity IgE Fc receptor.

\section{Authors' contributions}

JG for designing, executing the overall experiments, and contributing to the draft; ICW for determining purity of mast cells; LS for validating APC function and data analysis; MC for providing and guiding PCCP presentation system; NSY for data analysis and editing; FTL for conception, designing, supervising and writing the manuscript; SSC for conception, designing, supervising and writing the manuscript. All authors read and approved the manuscript.

\section{Acknowledgements}

This study is supported by a grant of NIH (U19 Al-42244) to FT Liu and SS Chen, and grants of NIH (Al-054075, Al-045902) to SS Chen.

\section{Author Details}

1Department of Allergy and Immunology, IgE Therapeutics, Inc., San Diego, CA, USA, ${ }^{2}$ Agriculture Biotechnology Research Center, Academia Sinica, Taipei, Taiwan, ${ }^{3}$ Division of Molecular Immunology, La Jolla Institute for Allergy and Immunology, San Diego, CA, USA, ${ }^{4}$ Department of Dermatology, University of California-Davis, Sacramento, CA, USA and 5Department of Molecular Biology, The Scripps Research Institute, San Diego, CA, USA

Received: 8 January 2010 Accepted: 30 June 2010

Published: 30 June 2010

\section{References}

1. Galli S, Tsai M, Piliponsky A: The development of allergic inflammation. Nature 2008, 454:445-454

2. Yu M, Tsai M, Tam S, Jones C, Zehnder J, Galli S: Mast cells can promote the development of multiple features of chronic asthma in mice. J Clin Invest 2006, 116:1633-1641.

3. Malaviya R, Ross E, Jakschik BA, Abraham SN: Mast cell degranulation induced by type 1 fimbriated Escherichia coli in mice. J Clin Invest 1994, 93:1645-1653.

4. Echtenacher B, Mannel DN, Hultner L: Critical protective role of mast cells in a model of acute septic peritonitis. Nature 1996, 381:75-77.

5. Nakano T, Sonoda T, Hayashi C, Yamatodani A, Kanayama Y, Yamamura T, Asai $\mathrm{H}$, Yonezawa T, Kitamura Y, Galli SJ: Fate of bone marrow-derived cultured mast cells after intracutaneous, intraperitoneal, and intravenous transfer into genetically mast cell- deficient $\mathrm{W} / \mathrm{Wv}$ mice. Evidence that cultured mast cells can give rise to both connective tissue type and mucosal mast cells. J Exp Med 1985, 162:1025-1043.

6. Kitamura Y: Heterogeneity of mast cells and phenotypic change between subpopulations. Annu Rev Immunol 1989, 7:59-76.

7. Tsai M, Shih LS, Newlands GF, Takeishi T, Langley KE, Zsebo KM, Miller HR, Geissler EN, Galli SJ: The rat c-kit ligand, stem cell factor, induces the 
development of connective tissue-type and mucosal mast cells in vivo. Analysis by anatomical distribution, histochemistry, and protease phenotype. J Exp Med 1991, 174:125-131.

8. Malaviya R, Twesten NJ, Ross EA, Abraham SN, Pfeifer JD: Mast cells process bacterial Ags through a phagocytic route for class I MHC presentation to T cells. J Immunol 1996, 156:1490-1496.

9. Frandji P, Mourad W, Tkaczyk C, Singer M, David B, Colle JH, Mecheri S: IL-4 mRNA transcription is induced in mouse bone marrow-derived mast cells through an MHC class II-dependent signaling pathway. Eur J Immunol 1998, 28:844-854.

10. Chen S, Cerny J: Studies on hapten-specific B cell tolerance in vitro. I. The inductive phase of central B cell tolerance. J Immunol 1980, 125:1962-1969.

11. Hirsch S, Austyn JM, Gordon S: Expression of the macrophage-specific antigen $\mathrm{F} 4 / 80$ during differentiation of mouse bone marrow cells in culture. J Exp Med 1981, 154:713-725.

12. Yen A, Liu FT, Barrett KE, Gigli I: Alterations in Fc epsilon RI induced by protoporphyrin plus long-wavelength ultraviolet light in mouse bone marrow-derived mast cells. J Immunol 1993, 151:1003-1011.

13. Ryan JJ, Huang H, McReynolds LJ, Shelburne C, Hu-Li J, Huff TF, Paul WE: Stem cell factor activates STAT-5 DNA binding in IL-3-derived bone marrow mast cells. Exp Hematol 1997, 25:357-362.

14. Razin E, Mencia Huerta JM, Stevens RL, Lewis RA, Liu FT, Corey E, Austen KF: IgE-mediated release of leukotriene C4, chondroitin sulfate $\mathrm{E}$ proteoglycan, beta-hexosaminidase, and histamine from cultured bone marrow-derived mouse mast cells. J Exp Med 1983, 157:189-201.

15. Tanaka S, Deai K, Inagaki M, Ichikawa A: Uptake of histamine by mouse peritoneal macrophages and a macrophage cell line, RAW264.7. Am J Physiol Cell Physiol 2003, 285:C592-598.

16. Dvorak A, Seder R, Paul W, Morgan E, Galli S: Effects of interleukin-3 with or without the c-kit ligand, stem cell factor, on the survival and cytoplasmic granule formation of mouse basophils and mast cells in vitro. Am J Pathol 1994, 144:160-170.

17. Dubey C, Croft M, Swain SL: Costimulatory requirements of naive CD4+ T cells. ICAM-1 or B7-1 can costimulate naive CD4 T cell activation but both are required for optimum response. J Immunol 1995, 155:45-57.

18. Bischoff SC, Sellge G, Lorentz A, Sebald W, Raab R, Manns MP: IL-4 enhances proliferation and mediator release in mature human mast cells. Proc Natl Acad Sci 1999, 96:8080-8085.

19. Frandji P, Oskeritzian C, Cacaraci F, Lapeyre J, Peronet R, David B, Guillet JG, Mecheri S: Antigen-dependent stimulation by bone marrow-derived mast cells of MHC class II-restricted T cell hybridoma. J Immunol 1993, 151:6318-6328

20. Levi-Schaffer F, Dayton ET, Austen KF, Hein A, Caulfield JP, Gravallese PM, Liu FT, Stevens RL: Mouse bone marrow-derived mast cells cocultured with fibroblasts. Morphology and stimulation-induced release of histamine, leukotriene B4, leukotriene $\mathrm{C} 4$, and prostaglandin D2. J Immunol 1987, 139:3431-3441.

21. Karasuyama H, Mukai K, Tsujimura Y, Obata K: Newly discovered roles for basophils: a neglected minority gains new respect. Nat Rev Immunol 2009, 9:9-13.

22. Kojima T, Obata, Kazushige, Mukai , Kaori, Sato, Shingo, Takai, Toshiyuki - Minegishi, Yoshiyuki, Karasuyama, Hajime : Mast Cells and Basophils Are Selectively Activated In Vitro and In Vivo through CD200R3 in an IgE-Independent Manner. J Immunol 2007, 179:7093-7100.

23. Edward F, Knol aBFG: Editorial: Basophil survival and immunomodulatory function are uniquely regulated by a novel MyD88-dependent pathway. J Leukoc Biol 2009, 86:753-755.

24. Sullivan B, Locksley RM: Basophils: a nonredundant contributor to host immunity. Immunity 2009, 30:12-20.

25. Ryan JJ, Kinzer CA, Paul WE: Mast cells lacking the high affinity immunoglobulin E receptor are deficient in Fc epsilon RI gamma messenger RNA. J Exp Med 1995, 182:567-574.

26. Kinzer $C A$, Keegan AD, Paul WE: Identification of Fc epsilon Rlneg mast cells in mouse bone marrow cell cultures. Use of a monoclonal antip161 antibody. J Exp Med 1995, 182:575-579.

27. Schmaltz R, Wang Y-Y, Kung Q-X, Liu F-T, Petro T, Chen S-S: B cell hybridoma presents both B-cell and T-cell epitopes for stimulating antibody production via CD23 pathway. Immunol Invest 1996, 25(56):481-493.
28. Galli SJ, Grimbaldeston M, Tsai M: Immunomodulatory mast cells: negative, as well as positive, regulators of immunity. Nat Rev Immunol 2008, 8:478-486

29. Grimbaldeston MA, Nakae S, Kalesnikoff J, Tsai M, Galli SJ: Mast cellderived interleukin 10 limits skin pathology in contact dermatitis and chronic irradiation with ultraviolet B. Nat Immunol 2007, 8:1095-1104.

30. Lu L-F, Lind EF, Gondek DC, Bennett KA, Gleeson MW, Pino-Lagos K, Scott ZA, Coyle AJ, Reed JL, Van Snick J, et al:: Mast cells are essential intermediaries in regulatory T-cell tolerance. Nature 2006 442:997-1002

31. Raposo G, Tenza D, Mecheri S, Peronet R, Bonnerot C, Desaymard C: Accumulation of Major Histocompatibility Complex Class II Molecules in Mast Cell Secretory Granules and Their Release upon Degranulation. Molecular Biology of the Cell 1997, 8:2631-2645.

32. Vincent-Schneider H, Stumptner-Cuvelette P, Lankar D, Pain S, Raposo G, Benaroch P, Bonnerot C: Exosomes bearing HLA-DR1 molecules need dendritic cells to efficiently stimulate specific T cells. Int Immunol 2002, 14:713-722.

33. Skokos D, Botros HG, Demeure C, Morin J, Peronet R, Birkenmeier G, Boudaly S, Mecheri S: Mast Cell-Derived Exosomes Induce Phenotypic and Functional Maturation of Dendritic Cells and Elicit Specific Immune Responses In Vivo. J Immuno/ 2003, 170:3037-3045.

34. Wynn TA: Basophils trump dendritic cells as APCs for $\mathrm{TH} 2$ responses. Nat Immunol 2009, 10:679-681.

35. Kalesnikoff J, Galli S: New developments in mast cell biology. Nat Immunol 2008, 9:1215-1223.

doi: 10.1186/1471-2172-11-34

Cite this article as: Gong et al., The antigen presentation function of bone marrow-derived mast cells is spatiotemporally restricted to a subset expressing high levels of cell surface Fc?RI and MHC II BMC Immunology 2010, 11:34

\section{Submit your next manuscript to BioMed Centra and take full advantage of:}

- Convenient online submission

- Thorough peer review

- No space constraints or color figure charges

- Immediate publication on acceptance

- Inclusion in PubMed, CAS, Scopus and Google Scholar

- Research which is freely available for redistribution 